\title{
Integrating Syngas Fermentation into a Single-Cell Microbial Electrosynthesis (MES) Reactor
}

\author{
Vasan Sivalingam (D), Vafa Ahmadi, Omodara Babafemi and Carlos Dinamarca * \\ Department of Process, Energy and Environmental Technology, University of South-Eastern Norway, \\ 3918 Porsgrunn, Norway; vasan.sivalingam@usn.no (V.S.); vvaaffaaahmadi@gmail.com (V.A.); \\ omodarafemi@yahoo.com (O.B.) \\ * Correspondence: carlos.dinamarca@usn.no
}

\begin{abstract}
This study presents a series of experiments to test the integration of syngas fermentation into a single-cell microbial electrosynthesis (MES) process. Minimal gas-liquid mass transfer is the primary bottleneck in such gas-fermentation processes. Therefore, we hypothesized that MES integration could trigger the thermodynamic barrier, resulting in higher gas-liquid mass transfer and product-formation rates. The study was performed in three different phases as batch experiments. The first phase dealt with mixed-culture fermentation at 1 bar $\mathrm{H}_{2}$ headspace pressure. During the second phase, surface electrodes were integrated into the fermentation medium, and investigations were performed in open-circuit mode. In the third phase, the electrodes were poised with a voltage, and the second phase was extended in closed-circuit mode. Phase 2 demonstrated three times the gas consumption $(1021 \mathrm{mmol})$ and $63 \%$ more production of acetic acid $(60 \mathrm{mmol} / \mathrm{L})$ than Phase 1 . However, Phase 3 failed; at $-0.8 \mathrm{~V}$, acetic acid was oxidized to yield hydrogen gas in the headspace.
\end{abstract}

Keywords: hydrogen; syngas; homoacetogenesis; pressure reactor; microbial electrosynthesis

Citation: Sivalingam, V.; Ahmadi, V.; Babafemi, O.; Dinamarca, C. Integrating Syngas Fermentation into a Single-Cell Microbial Electrosynthesis (MES) Reactor. Catalysts 2021, 11, 40. https://doi.org/10.3390/catal11010040

Received: 30 November 2020 Accepted: 28 December 2020 Published: 31 December 2020

Publisher's Note: MDPI stays neutral with regard to jurisdictional clai$\mathrm{ms}$ in published maps and institutional affiliations.

Copyright: $(\odot 2020$ by the authors. Licensee MDPI, Basel, Switzerland. This article is an open access article distributed under the terms and conditions of the Creative Commons Attribution (CC BY) license (https:// creativecommons.org/licenses/by/ $4.0 /)$.

\section{Introduction}

Pyrolysis and gasification technologies are attractive organic waste decomposition strategies that result in a gaseous product known as syngas, which is a mixture of carbon monoxide $(\mathrm{CO})$, carbon dioxide $\left(\mathrm{CO}_{2}\right)$, and hydrogen $\left(\mathrm{H}_{2}\right)$. Due to its energy content, syngas is considered as an energy vector for heat- and power-generation processes [1]. $\mathrm{CO}_{2}$, the final product of such processes, has no energy value, and requires a further capturing process. A typical $\mathrm{CO}_{2}$ capturing process involves either a chemical or mass transfer. Such methods are energy-intensive and expensive. Homoacetogens are microorganisms that perform $\mathrm{CO}_{2}$ fixation at room temperature and pressure using hydrogen gas as the energy source. Therefore, syngas fermentation in a homoacetogenic culture has been considered as one of the most sustainable methods of $\mathrm{CO}_{2}$ fixing.

The $\mathrm{CO}$ present in the syngas mixture can serve as both the carbon and energy source for fermentation, while $\mathrm{CO}_{2}$ and $\mathrm{H}_{2}$ serve only as the carbon and energy sources, respectively. Acetate is the primary end-product of homoacetogenesis (Equation (1)). Acetate synthesis from $\mathrm{CO}_{2}$ and $\mathrm{H}_{2}$ flows through the acetyl-CoA pathway, an intermediate reductive pathway also known as the Wood-Ljungdahl (WLJ) pathway [2]. The primary challenge in this fermentation process is the gas-liquid mass transfer, especially for hydrogen gas, which has lower solubility. Increasing the gas headspace pressure is one approach to improve the gas solubility and, consequently resulting in the gas-liquid mass transfer and product formation [3].

$$
4 \mathrm{H}_{2}+2 \mathrm{CO}_{2} \rightarrow \mathrm{CH}_{3} \mathrm{COOH}+2 \mathrm{H}_{2} \mathrm{O} \Delta \mathrm{G}^{0}=-74.3 \mathrm{~kJ} / \mathrm{mol}
$$

Microbial electrosynthesis (MES) is an evolving bioprocess that transforms electrical energy into chemical energy. It uses $\mathrm{CO}_{2}$ as the substrate to synthesis-reduced forms of 
carbon compounds, such as methane, acetate, and other short- and medium-chain acids and alcohols $[4,5]$. Renewable energy is used to keep the desired potential at the cathode $[6,7]$. The mild potential induces nonspontaneous reactions to overcome the thermodynamic barrier [8] and reduces the activation energy. Microorganisms present at the cathode are specific to the applied potential, and consequently synthesize particular products. For example, methane synthesis from $\mathrm{CO}_{2}$ occurs at $-0.65 \mathrm{~V}$, while acetate formation requires a more negative potential [9]. Reducing $\mathrm{CO}_{2}$ into valuable organic chemicals is receiving more attention than transforming it into methane [10-12] due to challenges in handling gaseous products and the demand for the synthesized organic chemicals.

This research investigated the impact of the partial pressure of hydrogen gas on the gas consumption rate increment as a baseline. The process was extended by introducing MES to increase the gas consumption rate even further. The experiment was performed in three successive phases: (1) A mixed-culture homoacetogenic reactor was pressurized with hydrogen gas, and the gas uptake rate and fermentation products were investigated; (2) Phase 1 was repeated with surface-electrodes installed in the reactor, which was operated in open-circuit mode (OCM); and (3) Phase 2 was continued in closed-circuit mode (CCM).

Having only $\mathrm{H}_{2}$ gas in the headspace simplified the experiments; therefore, the syngas was mimicked as a mixture of $\mathrm{CO}_{2}$ and $\mathrm{H}_{2}$. Only pure $\mathrm{H}_{2}$ was supplied in the headspace at approximately one bar elevated pressure, while $\mathrm{CO}_{2}$ was provided indirectly as sodium bicarbonate salt in the liquid medium $[5,13]$. During the two-month operation period, hydrogen gas consumption ceased. After that, the MES process was integrated within the elevated pressure in the syngas fermentation reactor, with the intention to enhance the gas uptake and product formation rate.

Elevating the partial pressure of a gas increases its solubility and consumption rate. Many studies of MES integration with fermentation to enhance gas uptake and product synthesis have been performed. However, most studies were carried out in two-chamber MES reactors [5,11,14], which mainly focus on $\mathrm{CO}_{2}$ use and the formation of methane and acetic acid. A two-chamber reactor arrangement is mostly preferred for MES because the oxygen gas evolution at the anode could poison the anaerobic environments by oxidizing the redox species. No known studies have examined a single-cell MES to enhance $\mathrm{H}_{2}$ gas consumption rate in a mixed-culture homoacetogenic syngas fermentation process. However, Nelabhotla and Dinamarca have performed several MES experiments with a single-cell MES reactor setup, and found a significantly higher product-synthesis efficiency without oxygen gas evolution [15-17]. These studies also sought to decrease the $\mathrm{CO}_{2}$ content in the biogas.

\section{Results and Discussion}

\subsection{Experimental Results}

The pressure time series and cumulative hydrogen-consumption profiles found in Phases 1 and 2 are shown in Figures 1 and 2, respectively. The hydrogen pressure drop was significantly improved by the presence of biofilm in Phase 2 . Phase 1, which was conducted without biofilm, had a shorter lag phase, but also a slower and limited $\mathrm{H}_{2}$ consumption rate, which flattened at the 10th injection (Figure 1a) when the accumulated hydrogen uptake reached $342 \mathrm{mmol}$ (Figure 2). In comparison, the reactor run with electrodes had a longer lag phase, with a higher $\mathrm{H}_{2}$ consumption rate that resulted in a total hydrogen accumulation of $1021 \mathrm{mmol} \mathrm{H}_{2}$ (Figure 2). The key results from Phases 1 and 2 are shown in Table 1. 


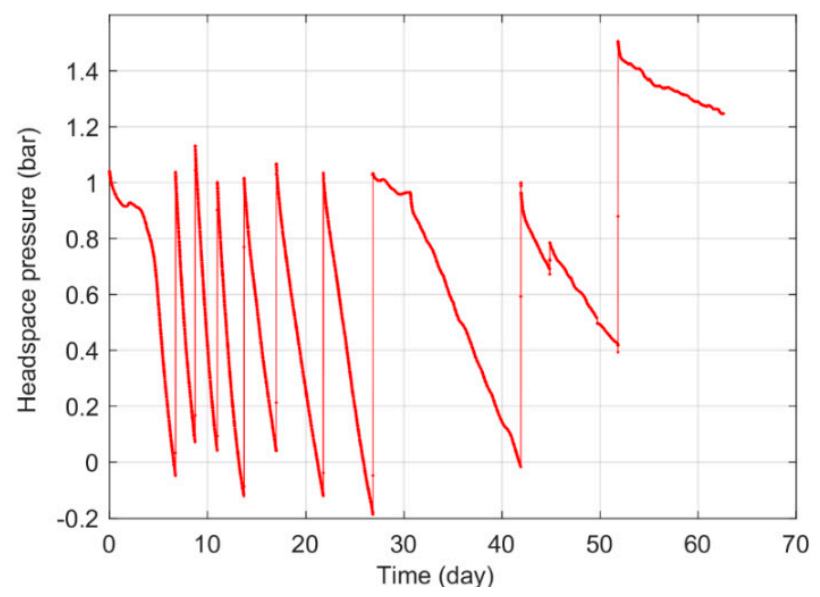

(a)

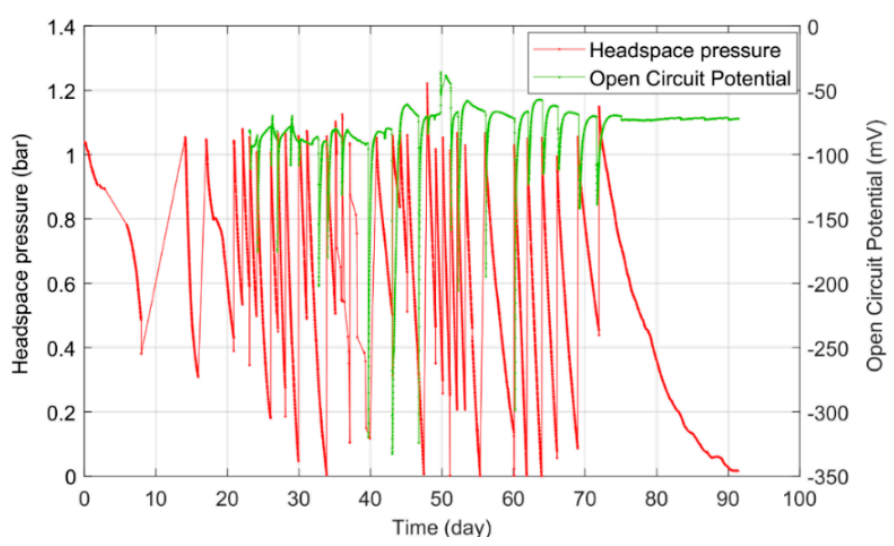

(b)

Figure 1. (a) The Phase 1 headspace pressure time series; (b) the Phase 2 headspace pressure time series and $\mathrm{OCM}$ at the cathode vs. the reference electrode $(\mathrm{Ag} / \mathrm{AgCl}, 3 \mathrm{M} \mathrm{NaCl})$.

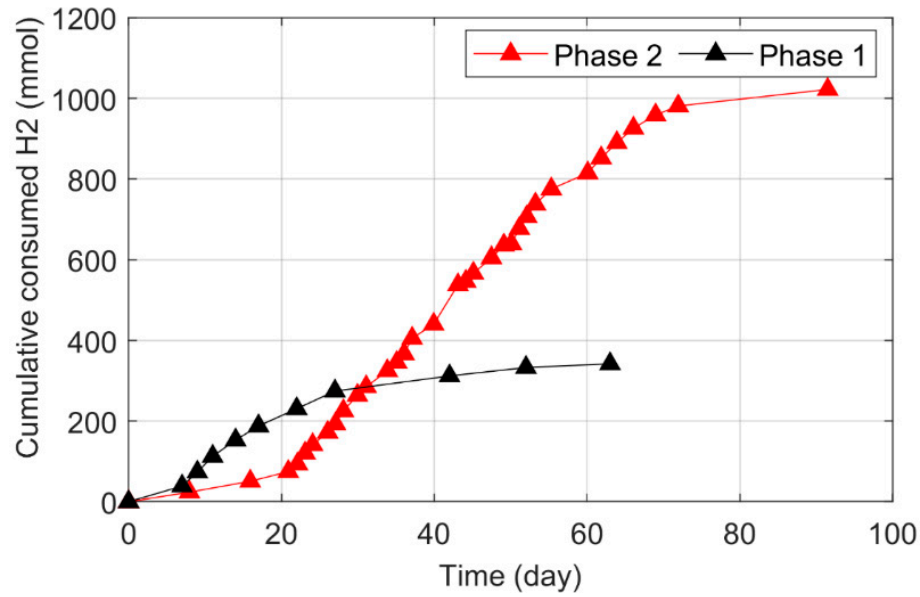

Figure 2. The cumulative hydrogen-consumption profiles for Phases 1 and 2. 
Table 1. The comparison of essential results for Phases 1 and 2.

\begin{tabular}{ccc}
\hline Measures & Phase 1 & Phase 2 \\
\hline Highest achieved gas uptake rate $(\mathrm{mmol} / \mathrm{L} \cdot$ day) & 6 & 13.5 \\
Time to reach the highest gas uptake rate (day) & 11 & 43 \\
Total consumed $\mathrm{H}_{2}(\mathrm{mmol})$ & 342 & 1021 \\
Time to reach the saturated gas consumption level (day) & 60 & 90 \\
Highest acetic acid concentration $(\mathrm{mmol} / \mathrm{L})$ & 35 & 57 \\
Acetic acid content in total VFAs $(\%)$ & 80 & 85 \\
\hline
\end{tabular}

The total amount of consumed $\mathrm{H}_{2}$ gas and the gas uptake rate during Phase 2 was 3 and 2.3 times higher than during Phase 1, respectively, and there was $63 \%$ more acetic acid production during Phase 2 (Figure $3 \mathrm{~b}$ ). Phase 2 required 90 days to reach the saturation level, while Phase 1 required only 60 days. The relative abundance of active biofilm on the electrodes caused more $\mathrm{H}_{2}$ gas dissociation and enhanced the acetic acid synthesis. In both phases, acetic acid was the primary product of the total VFAs matrix.

The open-circuit potential in Phase 2 is presented together with the headspace pressure change in Figure 1b. During the first two weeks of the experiment, the gas consumption rate was significantly lower. The rate then began to increase, and reached $13.5 \mathrm{mmol} / \mathrm{L} \cdot$ day on day 43 , then subsequently slowed to zero by the end of day 90 . During the first 60 days, the OCP fluctuated widely between -350 and $-80 \mathrm{mV}$, and then reached a stable range of around $-70 \mathrm{mV}$ on day 75 . This could be a notable indication of a steady biofilm on the cathode.

When a saturation in gas consumption and a stable OCP were reached, the reactor was pressurized with $\mathrm{H}_{2}$ to $1 \mathrm{bar}$, and the cathode was poised with $-0.8 \mathrm{~V}$. We expected to observe a higher gas consumption during Phase 3; however, the reactor behaved in the opposite manner, and an increase in headspace pressure was observed due to significant acetate oxidation. The headspace was depressurized when it rose above 1 bar to avoid reactor rupture, and the gas was collected to perform a composition analysis. Even though the reactor produced gas instead of uptaking it, we decided to continue with Phase 3, and quantified the product formation and gas composition for a short time. We think that sharing these negative results could be a good starting point for the development of a process integration.

Phase 3 was prolonged for 10 more days. Figure 3 a shows the gas-composition variation and the generated current. At the beginning of Phase $3, \mathrm{H}_{2}$ was the only gas product $(100 \%)$. After five days of operation, a trace amount $(3 \%)$ of $\mathrm{CO}_{2}$ started to evolve, followed by methane $\left(\mathrm{CH}_{4}\right)$ evolution $(6 \%)$ on day 7 . The $\mathrm{H}_{2}$ gas occupied more than $90 \%$ of the headspace. It is difficult to conclude whether the produced hydrogen had an abiotic or biotic origin; this will require several more experiments at different potentials to establish the shares of hydrogen production. However, the decrease in acetic acid concentration (Figure $3 b$ ) in CCM partially confirmed that hydrogen could be produced abiotically at the cathode. The decline in acetic acid concentration implied that acetic acid could be the source of the protons and electrons for the produced gases.

There was no oxygen gas measured in the gas mixture. This absence confirmed that single-cell MES could be integrated with the fermentation process without any countereffect due to oxygen evolution at the anode, which may oxidize redox fermentation intermediates, reducing efficiency. If the oxygen evolution is considerably large, it could result in aerobic conditions in MES, which cause severe damage to the anaerobic fermentation process. At the start of CCM, the generated current was $-200 \mathrm{~mA}$, which was gradually raised, reaching a peak at $-600 \mathrm{~mA}$ (current density $=8.57 \mathrm{~A} / \mathrm{m}^{2}$ ) when methane was formed. After that, it fell to $-400 \mathrm{~mA}$ and remained stable.

Figure $3 \mathrm{~b}$ shows the generation of VFAs throughout Phases 2 and 3. Though acetic acid and propionic acid were the primary fermentation products, at the end of Phase 2, $85 \%$ of the total VFAs was acetic acid. The added amount of bicarbonate limited the 
concentration of VFAs. Once the CCM started, a reduction in acetic acid was observed, which corresponded to the rise in $\mathrm{H}_{2}$ evolution.

Even though the inoculum underwent heat treatment, methane production confirmed that methanogens could not be completely eliminated by heat treatment. However, during the first 96 days of operation, the reactor did not exhibit any methane evolution. Once the electrodes were poised with voltage only, methane evolution was observed. It appeared that the electroactive methanogens were activated during Phase 3 due to the applied potential.

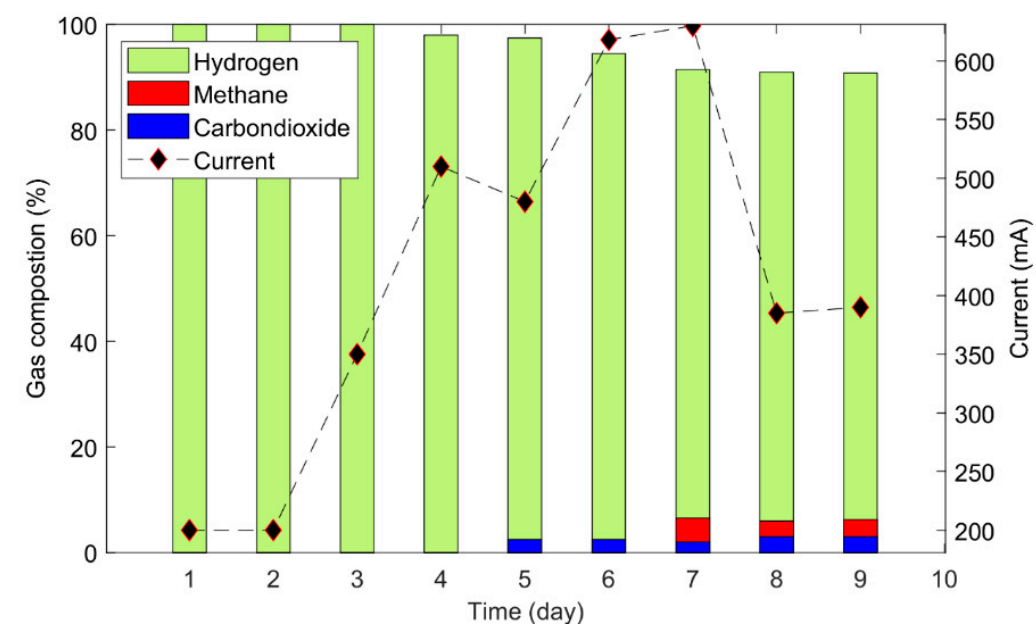

(a)

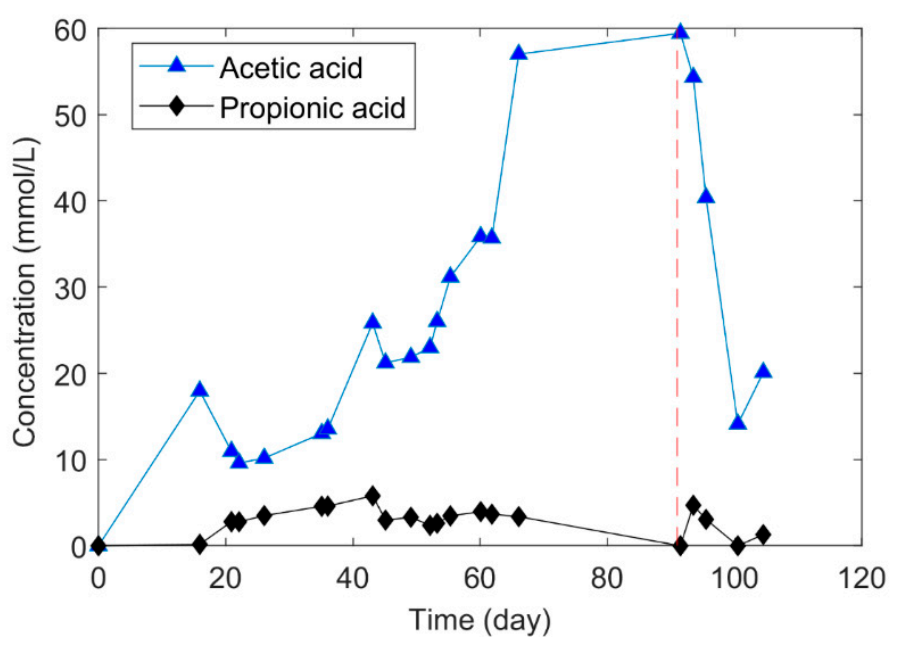

(b)

Figure 3. (a) The gas composition and the current variation during Phase 3. (b) The fermentationproduct formation throughout Phases 2 and 3 (separated by a red vertical line).

\subsection{Why Studying Bioelectrochemical-Mediated Syngas Fermentation Is Essential?}

The availability of organic waste will not be sufficient to meet the future demand for biomethane. It is expected that heavy transport, both land-based and maritime, will expand and diversify the use of this commodity, especially in Nordic countries. To meet this demand, it is necessary to increase production. The sources of organic waste for methane are limited, but $\mathrm{CO}_{2}$ from industrial exhaust is readily available, while equivalent electrons from water, sulfides, and ammonium are also available.

Additional methane can be co-generated during the bioelectrochemical reduction of $\mathrm{CO}_{2}$ and the fermentation of energy gases in one single reactor. Syngas can be converted 
directly to methane through hydrogenotrophic methanogenesis, or indirectly using acetate as an intermediate. To meet energy demands while safeguarding the environment with near-circular economy, we think that future biogas plants will use anaerobic digestion (AD), syngas fermentation, and bioelectrochemical systems (BES) in an integrated manner (Figure 4).

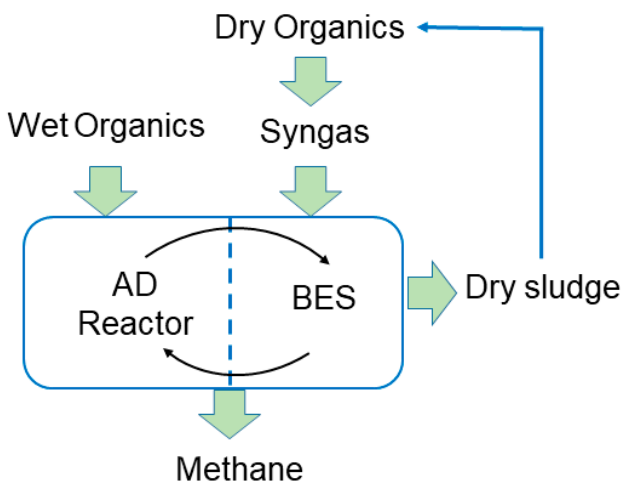

Figure 4. Integrated anaerobic digestion, syngas fermentation, and BES.

In an integrated AD-BES process as described by Nelabhotla and Dinamarca [10], an electric potential will drive electrons from water, organics, sulfides [18], and ammonium [7] to the cathode, where $\mathrm{CO}_{2}$ will be reduced to methane. We propose that methane can be produced from syngas using the same process. However, $\mathrm{H}_{2}, \mathrm{CO}$, and $\mathrm{CO}_{2}$ may take different metabolic routes depending on the applied potential. Our experiment showed that in a BES system with a titanium-anode and carbon-felt cathode poised at a $-0.8 \mathrm{~V}$ potential, hydrogen was produced due to acetate oxidation, while the main goal was to achieve a higher rate of hydrogen consumption. This is because syngas cannot be injected directly to $\mathrm{AD}$ due to the higher partial pressure of hydrogen, which inhibited the propionate degradation that halts biogas production. We set a goal of a combining AD-BES with syngas fermentation. In that combined system, hydrogen gas is converted directly to either methane or acetic acid while avoiding acetic acid oxidation, as was observed in our study.

Although Phases 1 and 2 of our experiment demonstrated a promising value addition to the syngas fermentation process, we recognize that Phase 3 was a preliminary attempt to integrate a single-cell MES into a syngas fermentation to improve the gas consumption and product-formation rates. A detailed study of optimized voltage (which would facilitate an increase in the $\mathrm{H}_{2}$ gas-uptake rate and would not oxidize the acetic acid) is necessary for proper process implications. Microbial analysis was vital at every phase to better understand the biochemical process involved. However, this attempt at a successful process integration suggested that the voltage optimization and microbial consortia analysis are essential elements in future research. Mathematical models for the reactor and the processes are also important in verifying the experimental results, and could constitute the objective of future studies.

\section{Materials and Methods}

\subsection{Inoculum Preparation}

Anaerobic digested sludge from the local wastewater treatment plant (Knarrdalstrand, Porsgrunn, Norway) was used to seed the reactor. The inoculum went through several treatment steps. First, it was sieved via 600 microns and incubated at $35^{\circ} \mathrm{C}$ for a week to eliminate readily biodegradable organics. The inoculum was then heat-treated at $105^{\circ} \mathrm{C}$ for $48 \mathrm{~h}$ to eliminate methanogens, while spore-forming acetogens were retained. The fermentation medium was facilitated with a nutrient solution composed of a mixture of salts $(10 \mathrm{~mL} / \mathrm{L})$, trace elements $(10 \mathrm{~mL} / \mathrm{L})$, and vitamins $(10 \mathrm{~mL} / \mathrm{L})$. The nutrient solution's composition was adapted from a similar study performed by Dinamarca and Bakke [19] (Table 2). 
Table 2. The content of the nutrient base media used to support the growth of the homoacetogenic culture.

\begin{tabular}{ccc}
\hline Vitamin Solution $(\mathrm{g} / \mathrm{L})$ & Mineral Solution $(\mathrm{g} / \mathrm{L})$ & Salt Solution $(\mathrm{g} / \mathrm{L})$ \\
\hline Biotin: 0.02 & $\mathrm{MnSO}_{4} \cdot \mathrm{H}_{2} \mathrm{O}: 0.04$ & $\mathrm{NH}_{4} \mathrm{Cl}: 100$ \\
Folic acid: 0.02 & $\mathrm{FeSO}_{4} \cdot 7 \mathrm{H}_{2} \mathrm{O}: 2.7$ & $\mathrm{NaCl}_{10} 10$ \\
Pyridoxine hydrochloride: 0.1 & $\mathrm{CuSO}_{4} \cdot 5 \mathrm{H}_{2} \mathrm{O}: 0.055$ & $\mathrm{MgCl}_{2} \cdot 6 \mathrm{H}_{2} \mathrm{O}: 10$ \\
Riboflavin: 0.05 & $\mathrm{NiCl}_{2} \cdot 6 \mathrm{H}_{2} \mathrm{O}: 0.1$ & - \\
Thiamine: 0.05 & $\mathrm{ZnSO}_{4} \cdot 7 \mathrm{H}_{2} \mathrm{O}: 0.088$ & - \\
Nicotinic acid: 0.05 & $\mathrm{CoCl}_{2} \cdot 6 \mathrm{H}_{2} \mathrm{O}: 0.05$ & - \\
Pantothenic acid: 0.05 & $\mathrm{H}_{3} \mathrm{BO}_{3}: 0.05$ & - \\
Vitamin $\mathrm{B}_{12}: 0.001$ & - & - \\
p-aminobenzoic acid: 0.05 & - & - \\
Thioctic acid: 0.05 & - & - \\
\hline
\end{tabular}

\subsection{Phase 1}

Phase 1 of the experiment was performed in a 4.125 L borosilicate glass reactor (FG Mellum AS, Akershus, Norway). It was modified as a lab-scale bioelectrochemical syngas fermentation reactor with a maximum pressure tolerance of 3 bar. The reactor was filled with $3.25 \mathrm{~L}$ of treated inoculum with incorporated nutrient solution and $3.4 \mathrm{~g} \mathrm{NaHCO}_{3} / \mathrm{L}$ $\left(\mathrm{CO}_{2}\right)$. A Heidolph MR 3001 magnetic stirrer (Heidolph Instruments, Schwabach, Germany) was used to provide proper agitation at $1000 \mathrm{rpm}$. The inoculum was purged with $\mathrm{N}_{2}$ gas for $5 \mathrm{~min}$ to strip off the oxygen, followed by a flushing with pure hydrogen gas (laboratory $5.5=\geq 99.9995 \%$, Linde Gas AS, Oslo, Norway). The headspace pressure was then elevated to approximately 1 bar with $\mathrm{H}_{2}$, and the changes were logged using a CPG 1500 digital pressure gauge (WIKA, Bavaria, Germany) at $10 \mathrm{~min}$ intervals. Once the headspace pressure reached approximately zero, the reactor was repressurized to 1 bar and continued until no change in the pressure reading was observed. This experiment lasted 60 days.

\subsection{Electrode Design and Experimental Setup}

The anode and cathode were designed based on the reactor's volume to achieve the optimum surface area. Carbon felt $(3.18 \mathrm{~mm}$ thickness, $99.0 \% \approx 2.4 \mathrm{~g} / 10 \times 10 \mathrm{~cm}$ ) from Alfa Aesar (GmbH, Kandel, Germany) was used as the cathode. The cathode was framed with a titanium sheet $(1 \mathrm{~cm})$ to keep it stable inside the reactor, and wrapped with titanium wire to enhance the electrical contact. A titanium metal sheet was used as the anode. It was modified to a particular shape to fit into the reactor and achieve more efficient agitation of the fermentation medium (Figure 5). The designs of the anode and cathode and an upper cross-sectional view of the reactor is presented in Figure 1. The surface area of anode and cathode were approximately $700 \mathrm{~cm}^{2}$. An $\mathrm{Ag} / \mathrm{AgCl}$ electrode (3 M NaCl, QVMF2052, ProSense, BB Oosterhout, The Netherlands) was used as the reference electrode. A Gamry 1010B Potentiostat-Galvanostat-ZRA (Gamry Instruments, Philadelphia, PA, USA) was used to perform electrochemical measurements. 


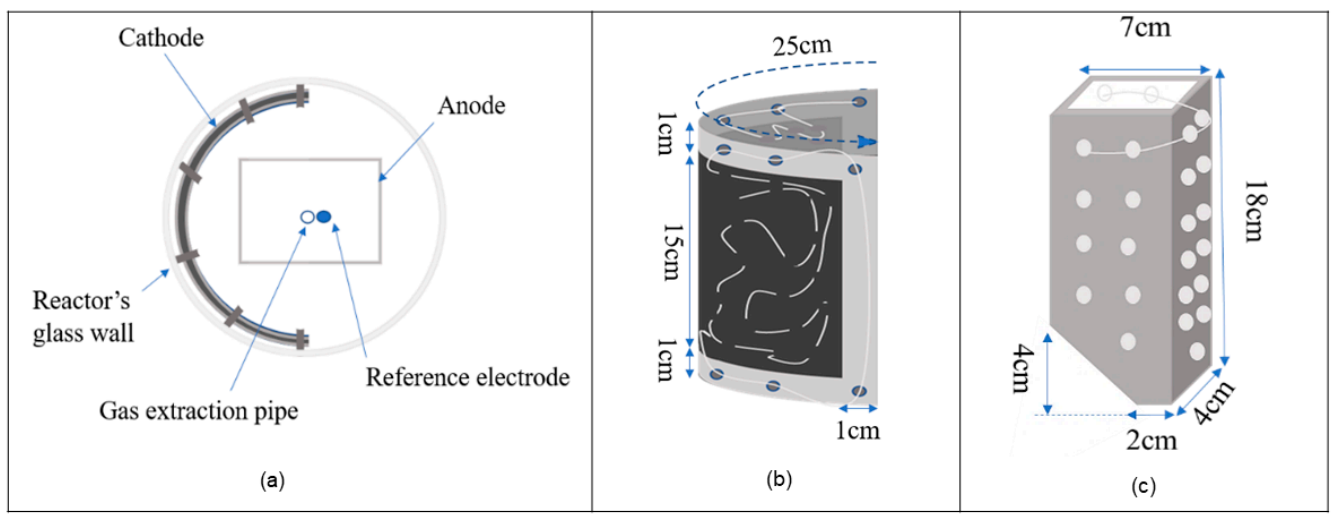

Figure 5. An upper cross-section of the reactor with electrode arrangements and electrode design with dimensions. (a) The upper cross-section, (b) the cathode, and (c) the anode.

\subsection{Phase 2: Open-Circuit Mode}

The electrodes were installed into the same glass reactor used in Phase 1 (Figure 6), and the Phase 1 procedure with fresh inoculum was repeated until it reached the stable headspace pressure. During this phase, the electrodes were not poised with voltage, and the experiments were performed in OCM. During this phase, it took 90 days to for the gas consumption or saturated gas consumption to cease.

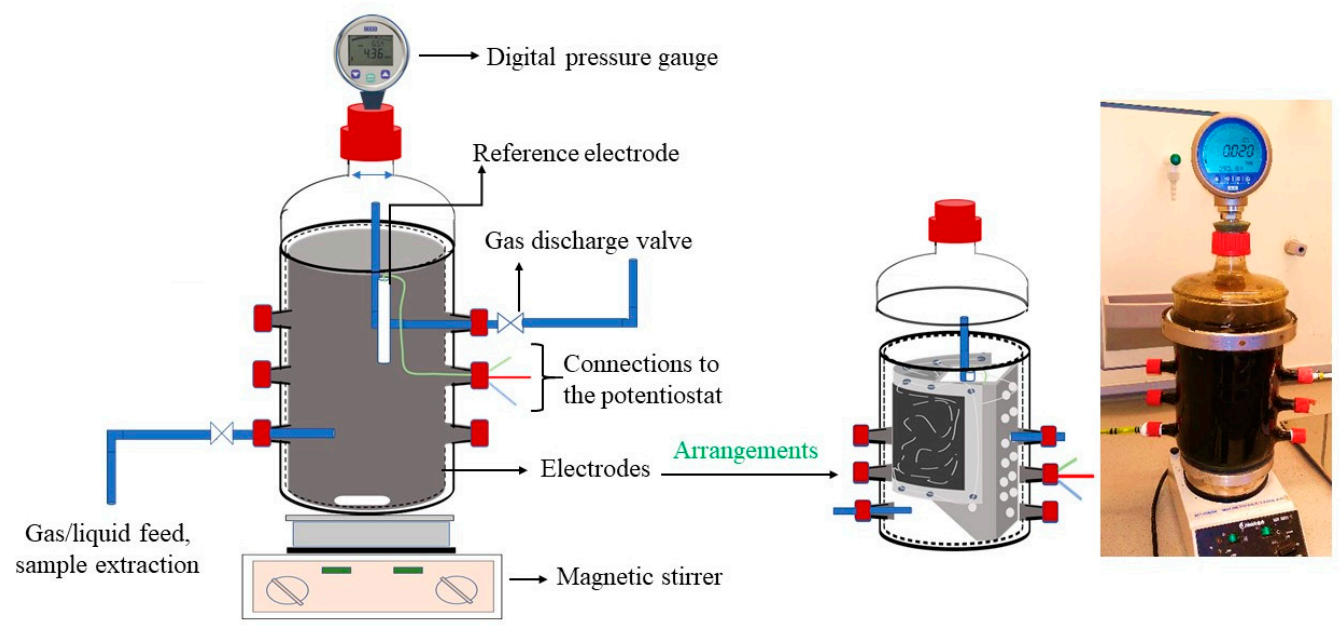

Figure 6. A sketch of the designed reactor (left), the anode and cathode arrangements within the reactor (center), and the complete reactor setup (right).

\subsection{Phase 3: Closed-Circuit Mode}

Once the saturated gas-consumption level was reached in Phase 2, it was prolonged in CCM. During CCM, the cathode was poised with $-0.8 \mathrm{~V}$ vs. SHE by using a Gamry 1010B Potentiostat-Galvanostat-ZRA (Gamry Instruments, Philadelphia, PA, USA). This particular potential value was selected in accordance with similar studies performed by Nelabhotla et al. [16], during which they observed significant acetic acid production within the potential range of -0.8 to $-0.9 \mathrm{~V}$ vs. SHE in a single-cell MES reactor.

We intended to pressurize the reactor with hydrogen gas during Phase 1 when the cathode was poised with $-0.8 \mathrm{~V}$. However, the reactor produced some gases $\left(\mathrm{H}_{2}, \mathrm{CH}_{4}\right.$, and $\mathrm{CO}_{2}$ ) when the cathode was poised with voltage, so the hydrogen feeding was stopped. Since the glass rector had limited pressure tolerance, the gas that accumulated in the headspace was released when it approached 1 bar of pressure, and gas composition analyses were performed, along with measurements of volatile fatty acids (VFAs). 


\subsection{Analytical Measurements}

The concentration of VFAs was measured using a Clarius 500 PE auto-system gas chromatograph integrated with a built-in autosampler (Perkin Elmer, Waltham, MA, USA). The instrument was equipped with a capillary column (scion-wax temperature $20-250{ }^{\circ} \mathrm{C}$ ) and a flame ionization detector (FID). The dimensions of the column were $25 \mathrm{~m}$ length, $0.25 \mathrm{~mm}$ diameter, and $0.2 \mu \mathrm{m}$ film. The carrier gas was $\mathrm{H}_{2}$ at a rate of $45 \mathrm{~mL} / \mathrm{min}$. The injector and detector temperatures were 270 and $250{ }^{\circ} \mathrm{C}$, respectively. The initial oven temperature was set at $80^{\circ} \mathrm{C}$ and maintained for $0.7 \mathrm{~min}$, then was increased at a rate of $25^{\circ} \mathrm{C} / \mathrm{min}$ to $200^{\circ} \mathrm{C}$, followed by $20^{\circ} \mathrm{C}$ increments until attaining an operating temperature of $240{ }^{\circ} \mathrm{C}$.

The gas-composition analyses were performed using an 8610C gas chromatograph (SRI Instruments, Torrance, CA, USA) equipped with 6' Haysep-D (MXT-1) and 6' Molecular Sieve (MS13X) columns. The oven was operated at a constant $80^{\circ} \mathrm{C}$, with helium as the carrier gas at 2.1 bar pressure and a $20 \mathrm{~mL} / \mathrm{min}$ flow rate. The thermal conductivity detector (TCD) was operated at $150{ }^{\circ} \mathrm{C}$ with helium and airflow rates of 25 and $250 \mathrm{~mL} / \mathrm{min}$, respectively.

\section{Conclusions}

The biofilm that formed on the electrodes facilitated an $\mathrm{H}_{2}$ gas dissociation three times higher than the reactor without electrode surface, resulting in $63 \%$ more acetic acid production. Our hypothesis that an increase in gas consumption would be realized by negatively poising $-0.8 \mathrm{~V}$ at the cathode failed; instead, gas production was observed, with $90 \%$ of the gas in the form of hydrogen. The reduction in acetic acid concentration and the evolution of gaseous products occurred simultaneously, which suggested that hydrogen and $\mathrm{CO}_{2}$ products can be produced from acetic acid. As the findings of our study provided a good starting point toward integrating a successful syngas fermentation process into a single-cell AD-MES. The interface of MES and syngas fermentation could also be used to control product formation. Short-chain organic products can be obtained at a high rate due to the presence of densely packed biomass on the electrodes, and overproduced compounds can be oxidized as hydrogen gas to maintain target product concentration in the liquid medium.

Author Contributions: Conceptualization, C.D.; methodology, V.S. and C.D.; software, V.S., C.D., V.A., and O.B.; validation, V.S. and C.D.; formal analysis, V.S., C.D., V.A., and O.B.; investigation, V.S. and C.D.; resources, C.D.; data curation, V.S. and V.A.; writing-original draft preparation, V.S.; writing-review and editing, V.S. and C.D.; visualization, V.S.; supervision, C.D.; project administration, C.D.; funding acquisition, C.D. All authors have read and agreed to the published version of the manuscript.

Funding: This research was funded by the Norwegian Ministry of Education and Research through the Ph.D. program in Process, Energy and Automation Engineering at the University of South-Eastern Norway, grant number 2700095. The University of South-Eastern Norway funded the APC.

Acknowledgments: The authors wish to thank the Norwegian Ministry of Education and Research for funding.

Conflicts of Interest: The authors declare no conflict of interest.

\section{References}

1. Solarte-Toro, J.C.; Chacón-Pérez, Y.; Cardona-Alzate, C.A. Evaluation of biogas and syngas as energy vectors for heat and power generation using lignocellulosic biomass as raw material. Electron. J. Biotechnol. 2018, 33, 52-62. [CrossRef]

2. Phillips, J.R.; Huhnke, R.L.; Atiyeh, H.K. Syngas fermentation: A microbial conversion process of gaseous substrates to various products. Fermentation 2017, 3, 28. [CrossRef]

3. Stoll, I.; Herbig, S.; Zwick, M.; Boukis, N.; Sauer, J.; Neumann, A.; Oswald, F. Fermentation of $\mathrm{H}_{2}$ and $\mathrm{CO}_{2}$ with clostridium ljungdahlii at elevated process pressure-First experimental results. Chem. Eng. Trans. 2018, 64, 151-156.

4. Ganigué, R.; Puig, S.; Batlle-Vilanova, P.; Balaguer, M.D.; Colprim, J. Microbial electrosynthesis of butyrate from carbon dioxide. Chem. Commun. 2015, 51, 3235-3238. [CrossRef] 
5. Mohanakrishna, G.; Abu Reesh, I.M.; Vanbroekhoven, K.; Pant, D. Microbial electrosynthesis feasibility evaluation at high bicarbonate concentrations with enriched homoacetogenic biocathode. Sci. Total Environ. 2020, 715, 137003. [CrossRef] [PubMed]

6. Rago, L.; Pant, D.; Schievano, A. Chapter 14-Electro-Fermentation-Microbial Electrochemistry as New Frontier in Biomass Refineries and Industrial Fermentations. In Advanced Bioprocessing for Alternative Fuels, Biobased Chemicals, and Bioproducts; Hosseini, M., Ed.; Woodhead Publishing: Cambridge, UK, 2019; pp. 265-287, ISBN 978-0-12-817941-3.

7. Sivalingam, V.; Dinamarca, C.; Samarakoon, G.; Winkler, D.; Bakke, R. Ammonium as a carbon-free electron and proton source in microbial electrosynthesis processes. Sustainability 2020, 12, 3081. [CrossRef]

8. Jiang, Y.; Jianxiong Zeng, R. Expanding the product spectrum of value added chemicals in microbial electrosynthesis through integrated process design-A review. Bioresour. Technol. 2018, 269, 503-512. [CrossRef] [PubMed]

9. Nelabhotla, A.B.T.; Dinamarca, C. Bioelectrochemical $\mathrm{CO}_{2}$ reduction to methane: MES integration in biogas production processes. Appl. Sci. 2019, 9, 1056. [CrossRef]

10. Nevin, K.P.; Hensley, S.A.; Franks, A.E.; Summers, Z.M.; Ou, J.; Woodard, T.L.; Snoeyenbos-West, O.L.; Lovley, D.R. Electrosynthesis of organic compounds from carbon dioxide is catalyzed by a diversity of acetogenic microorganisms. Appl. Environ. Microbiol. 2011, 77, 2882-2886. [CrossRef] [PubMed]

11. Jiang, Y.; Su, M.; Zhang, Y.; Zhan, G.; Tao, Y.; Li, D. Bioelectrochemical systems for simultaneously production of methane and acetate from carbon dioxide at relatively high rate. Int. J. Hydrogen Energy 2013, 38, 3497-3502. [CrossRef]

12. Lehtinen, T.; Efimova, E.; Tremblay, P.-L.; Santala, S.; Zhang, T.; Santala, V. Production of long chain alkyl esters from carbon dioxide and electricity by a two-stage bacterial process. Bioresour. Technol. 2017, 243, 30-36. [CrossRef] [PubMed]

13. del Pilar Anzola Rojas, M.; Zaiat, M.; Gonzalez, E.R.; De Wever, H.; Pant, D. Effect of the electric supply interruption on a microbial electrosynthesis system converting inorganic carbon into acetate. Bioresour. Technol. 2018, 266, 203-210. [CrossRef] [PubMed]

14. Batlle-Vilanova, P.; Puig, S.; Gonzalez-Olmos, R.; Balaguer, M.D.; Colprim, J. Continuous acetate production through microbial electrosynthesis from $\mathrm{CO}_{2}$ with microbial mixed culture. J. Chem. Technol. Biotechnol. 2016, 91, 921-927. [CrossRef]

15. Nelabhotla, A.B.T.; Khoshbakhtian, M.; Chopra, N.; Dinamarca, C. Effect of hydraulic retention time on MES operation for biomethane production. Front. Energy Res. 2020, 8. [CrossRef]

16. Nelabhotla, A.B.T.; Bakke, R.; Dinamarca, C. Performance analysis of biocathode in bioelectrochemical CO2 reduction. Catalysts 2019, 9, 683. [CrossRef]

17. Nelabhotla, A.B.T. Electrochemical Unit Integration with Biogas Production Processes. Ph.D. Thesis, University of South-Eastern Norway, Porsgrunn, Norway, 2020.

18. Bian, B.; Bajracharya, S.; Xu, J.; Pant, D.; Saikaly, P.E. Microbial electrosynthesis from $\mathrm{CO}_{2}$ : Challenges, opportunities and perspectives in the context of circular bioeconomy. Bioresour. Technol. 2020, 122863. [CrossRef] [PubMed]

19. Dinamarca, C.; Bakke, R. Apparent hydrogen consumption in acid reactors: Observations and implications. Water Sci. Technol. J. Int. Assoc. Water Pollut. Res. 2009, 59, 1441-1447. [CrossRef] [PubMed] 